\title{
Antioxidant therapy impresses in oxidative stress-induced kidney cells
}

\author{
Alpay $\mathrm{M}^{1}$, Kismali $\mathrm{G}^{2}$, Meral $\mathrm{O}^{1}$, Sel $\mathrm{T}^{2}$, Ozmerdivenli $\mathrm{R}^{3}$, Pasin $\mathrm{O}^{4}$ \\ Duzce University Faculty of Medicine, Department of Biochemistry, Duzce, Turkey. \\ mervealpay86@yahoo.com
}

\section{ABSTRACT}

INTRODUCTION: Renal cell cancer (RCC) is not a single entity, but consists of different types of tumors derived from various parts of the nephron (epithelium or renal tubules). It is known that cancer initiation and progression is related to the balance between oxidants and antioxidants directly. Interestingly, advanced stages of cancer such as metastasis, angiogenesis are associated with cell oxidative capacity. Familiar antioxidative substances such as carotenes and vitamin C inhibit oxidation of other molecules during carcinogenesis. They can define the distinction between cancer and normal cells, destroying cancer cells while stabilizing healthy cells. METHODS: apoptotic activities of kidney cells were measured with caspase Elisa kits. DNA laddering test was used to show DNA damage in $\mathrm{H}_{2} \mathrm{O}_{2}$ condition.

RESULTS: For tumor mechanism, they act as pro-oxidants, producing hydrogen peroxide that attacks the cancer, whereas, in normal conditions they act as protective antioxidants.

CONCLUSIONS: The unlike reaction of specific antioxidants should be known at different cell stages. The aim of this study was to assess the antioxidative roles of alpha lipoic acid on kidney cancers during oxidative stress induction (Tab. 1, Fig. 7, Ref. 27). Text in PDF www.elis.sk.

KEY WORDS: alpha lipoic acid, apoptosis, $\mathrm{H}_{2} \mathrm{O}_{2}$, kidney, ROS.

\section{Introduction}

Renal cell carcinoma is a type of kidney cancer which initiates with the proximal tubule, a part of the very small tubes in kidney that are responsible for transportation of waste molecules from the blood to the urine. In adults, approximately $90-95 \%$ of case of renal carcinoma are seen and each year 65,000 new cases of kidney malignancies are diagnosed, Epidemiologically, it is the seventh most common kind of cancer in men and the ninth most common in women (1).

Renal carcinoma occurs more likely from clear cells which are described as dissolving of the cells high lipid content in the cytoplasm. Researchers showed that clear cells can spread ones and more preferable to diagnosis and treatment. This occurs usually in 10-15\% types of RCC initiation. However, most of the tumours contain different origin of cells. While renal cancer is thought to contain a mix of both clear and granular cells, they act more aggressively, and assign difficult prognosis. Cell type is directly associated with renal malignancy (2).

This malignant tumor has several risk factors such as tobacco, obesity, hypertension, and physical inactivity, but direct mecha-

${ }^{1}$ Duzce University, Faculty of Medicine, Department of Biochemistry, Duzce, Turkey, ${ }^{2}$ Ankara University, Faculty of Veterinary Medicine, Department of Biochemistry, Ankara, Turkey, ${ }^{3}$ Duzce University, Faculty of Medicine, Department of Physiology, Duzce, Turkey, and ${ }^{4}$ Istanbul University, Faculty of Medicine, Department of Biostatistics, Istanbul, Turkey

Address for correspondence: Alpay M, Duzce University, Faculty of Medicine, Department of Biochemistry, Duzce, Turkey. nistic explanations have not yet been presented clearly, can be also genetic. Normally, oxidative stress haş been associated with degeneration of cell cycle. But it has also been related to the risk of RCC dueto changed metabolic hemodynamics stimulated by hypoxia factors (3).

Some reactions change physiological mechanism, for instance DNA damage. Every cell has DNA and impressed all per-actions. Depending on the physiological conditions, cells can behave as injured, death or adapted. They decide how to act aganist oncogenic factors. Cancer cells consist of starting DNA damaged cells. In normal conditions, when DNA gets damaged, the cell either repairs the damage or the cell dies. Despite that in cancer cells, the damaged DNA is not repaired, but the cell doesn't die like it should. Instead, this cell goes on making new cells that the body does not need. These fact accelerates carcinogenesis stage $(4,5)$.

Oxidative stress, which occurs due to an imbalance between oxidative free radical production and antioxidant activity, leads to cellular dysfunction. High amount of free radicals and decreased immune defense appear to be the link inflammation in dialysis patients. Moreover, renal tissue injury can cause nondialysis chronic kidney disease stage with oxidative mechanisms in which oxidative stress is directly related with the progression of kidney disease (6).

Researches have indicated more about the molecular and genetic changes in cells that cause cancer, trying to develop effective drugs that target some of these changes. These targeted drugs are different from standard chemotherapy drugs. They are more convenient drugs due to effect beyond standard chemo drugs, however target therapy focuses only on onco-cells and has less 
severe side effects. Renal carcinoma is one of the drug resistant malignancies in humans. Inrecent years targeted drugs are popular for treatment of kidney cancer, where traditional chemotherapy has not been shown to be very effective. The marked drugs arrest angiogenesis and decrease important proteins in cancer cells while retarding progression. Nevertheless clinical cure investigations, diagnosis, designing of prognostic biomarkers and targeted therapies are difficult to apply when heterogeneity of renal cell carcinoma (RCC) multiplies (7).

Researchers showed that the intake of flavonoids such as vitamins E, A that have antioxidant effects is directly associated with kidney cancer predisposing factors. Previous studies have suggested that renal carcinomas are insufficiently supplied with micronutrients through diet or dietary supplementation, including vitamins $\mathrm{C}$ and $\mathrm{E}$ and carotenoids that are able to inhibit oxidative DNA damage and tumor growth (8).

Chemopreventive natural products are promising to be developed in cancer therapy by suppresion of carcinogenesis, effect on cell cycle regulation, effect on apoptosis, effect on angiogenesis or metastasis. In vitro studies observed that phytochemicals while decreasing the toxicity on normal tissue, are increasing the efficiency on cancer tissue. Flavonoids are able to initiate proapoptotic stages through both the extrinsic and intrinsic apoptotic pathways, some of them regulated with FasL/TNFa mechanism activating caspase 8 , and oncoproteins can directly induce the mitochondrial regulation and result in activation of caspase $9(9,10)$.

Alpha lipoic acid (ALA) has natural antioxidant effects on scavenging reactive oxygen species and metal chelation by acting as an essential cofactor of metal-binding enzymes for mitochondrial respiration. ALA has also been shown to induce apoptosis in cancer cells. ALA has been reported to have beneficial effects in advanced cancers with direct anti-tumor activity by inhibiting cell proliferation by increasing the glutathione peroxidase activity and by reducing oxidative stress. ALA also prevents cell survival and inhibits lipopolysaccharide-induced inflammatory reactions by activating the phosphoinositide 3-kinase/Akt signalling pathway. Recent studies show that ALA plays essential role in NF- $\kappa B$ inhibition in kidney tissue, an action of immune suppression and inflammatory responses. Lipoic acid has unique benefits to improve potential renal function such as diabetes by lowering glycemia, however, the antioxidant and prooxidant mechanisms of a lipoic acid are not determined clearly $(11,12)$.

The other significant characteristic of alpha lipoic acid is that, since it is both water and fat soluble, ALA leads to inhibition of cell damage by neutralize free radicals with dietary effects. This step occurs by penetrating into whole cell parts. Some antioxidant units are soluble only in water such as vitamin $\mathrm{C}$, while some of them stick to the fatty parts of cells and are soluble only in fat as vitamin E. ALA is a sulfurous fatty acid. This essential compound would be recognized as a vitamin. ALA would stimulate other antioxidants through their active antioxidant form. These manifold effects have reported for an interaction with ascorbic acid, vitamin E, coenzyme Q10 and glutathione substances. Normal intake of LA has low toxicity but very large amounts are toxic (12).

Beneficial effect of alpha lipoic acid is determined between 10 $\mathrm{uM}$ and $300 \mathrm{uM}$ maximal plasma concentration depending on cell behaviour. When oral intake of ALA absorbtion is 93\%, 20-30 $\%$ is metabolized in the liver. Potential effects of LA identified in vitro experiments report that inhibiting oxidant molecules, scavenging free radicals, protecting against caspase 3 activation and inducing apoptosis on cancer cells (13).

Based on the knowledge of anticancer properties, the current study was aimed to determine the effects of alpha lipoic acid induced with $\mathrm{H}_{2} \mathrm{O}_{2}$ in renal cancer cells and its combination therapy with ALA.

\section{Material and methods}

A 498 (renal epithelial) cancer line was obtained from Ankara University Health science institute, Turkey and cultured as recommended by ATCC. They were maintained in RPMI 1640 (Invitrogen Co., USA) supplemented with $10 \%$ fetal bovine serum and penicillin $(100 \mathrm{Ag} / \mathrm{mL})$ and streptomycin $(100 \mathrm{Ag} / \mathrm{mL})$ in a humidified $5 \% \mathrm{CO}_{2}$ atmosphere at $37{ }^{\circ} \mathrm{C}$. All experiments were performed between passages 3 and 8 .

The effect of chemical agents on cell growth was assayed using the MTT method. Cells were seeded in 96-well plates, and cultured for $24 \mathrm{~h}$ in the presence or absence of DMSO. The cells were then placed in serum-free medium treated with $\mathrm{H}_{2} \mathrm{O}_{2}$ and ALA in the presence or absence of DMSO for $48 \mathrm{~h}$, after which $10 \mathrm{uL}$ of MTT solution was added and incubation was continued for 4 $\mathrm{h}$, then adding SDS $10 \%$ for dissolving formazan product. The cell absorbance was measured with a microplate reader (Bio-Rad, Hercules, CA, U.S.A.) at $570 \mathrm{~nm}$. Optimum $\mathrm{H}_{2} \mathrm{O}_{2}$ concentrations to induce DNA damage and ALA concentration for antioxidant treatment were detected.

For analysis of caspase enzymes release from A498 cell with tumor cell monolayers, cells were spun down, washed once with ice-cold PBS, and then once with ice-cold cell lysis buffer $(20 \mathrm{mM}$ Tris-HCl, $150 \mathrm{mM} \mathrm{NaCl}, 1 \mathrm{mM}$ Na2EDTA, 1 mM EGTA, $1 \%$ Triton, $20 \mathrm{mM}$ sodium Pyrophosphate, $25 \mathrm{mM}$ Sodium Fluoride, 1 $\mathrm{mM} \beta$-glycerophosphate, $1 \mathrm{mM} \mathrm{Na}_{3} \mathrm{VO}_{4}, 1 \mu \mathrm{g} / \mathrm{ml}$ leupeptin), containing $1 \mathrm{mM}$ protease inhibitors. The cell pellet was resuspended in $1 \mathrm{X}$ buffer, and following $20 \mathrm{~min}$ on ice for homogenization.

Tab. 1. Cell average after agent application.

\begin{tabular}{|c|c|c|c|c|c|c|}
\hline Group & Average & Median & Standard deviation & Minimum & Maximum & $\mathrm{p}$ \\
\hline control &, 78533 &, 78100 & ,009292 &, 779 &, 796 & \\
\hline $\mathrm{H}_{2} \mathrm{O}_{2}$ &, 28533 & ,28700 & 019553 &, 265 & ,304 & \\
\hline $\mathrm{ALA}^{2}$ &, 70567 &, 70100 & 011719 & 697 &, 719 & 0,009 \\
\hline $\mathrm{H}_{2} \mathrm{O}_{2}+\mathrm{ALA}$ &, 21333 &, 20200 &, 022279 &, 199 &, 239 & \\
\hline $\mathrm{H}_{2} \mathrm{O}_{2}+\mathrm{ALA}+5 \mathrm{fu}$ &, 17633 &, 17600 &, 014503 &, 162 &, 191 & \\
\hline
\end{tabular}


The homogenate was centrifuged at $1500 \mathrm{~g}$ for $10 \mathrm{~min}$, and the supernatant, which contained released caspase, assessed for protein concentration. Equivalent amounts of protein were prepared by BSA test for Caspases and COX analysis.

Quantification of cleaved Caspase 3 activity was performed using the PathScan Cleaved Caspase 3, Caspase 8, Caspase 9 sandwich ELISA kit (Cell Signaling Technology, USA) according to the manufacturer's recommendations. Caspase assay kit detects endogenous levels of cleaved caspase protein.

Another analysis to detect apoptosis phase, DNA laddering test (Chemicon, Temecula, CA, USA) was used. Cell pellet from experimental groups washed with PBS and centrifuged at 5000 rpm for $5 \mathrm{~min}$. After lysed cells, $5 \mathrm{ul}$ RNAse A and 5 ul proteinase $\mathrm{K}$ were added to expose DNA fragments. Then 30 min incubation at $50{ }^{\circ} \mathrm{C}$ was achieved. Ammonium acetate $(5 \mathrm{uL})$ applied to each sample was stored at $-20^{\circ} \mathrm{C}$ for $10 \mathrm{~min}$. After $15 \mathrm{~min}$ high speed centrifugation of precipitated DNA it was loaded on a $1 \%$ agarose gel to show DNA breaks ladder formation.

\section{Results}

Table 1 shows data statistics and $p$ value obtained from cell viability median between samples (control, $\mathrm{H}_{2} \mathrm{O}_{2}, \mathrm{ALA}, \mathrm{H}_{2} \mathrm{O}_{2}+\mathrm{ALA}$, $\left.\mathrm{H}_{2} \mathrm{O}_{2}+\mathrm{ALA}+5 \mathrm{FU}\right)$. Upon analyzing, the tableis indicating significant differences for cell viability median among control and application groups $(\mathrm{p}=0.009)$. When the differences are examined particularly (Fig. 1), $\mathrm{H}_{2} \mathrm{O}_{2}+\mathrm{ALA}+5 \mathrm{FU}$ group has significantly decreased compared to ALA and control groups $(\mathrm{p}=0.014, \mathrm{p}=$ $0.001), \mathrm{H}_{2} \mathrm{O}_{2}+\mathrm{ALA}$ group were significantly lower than control group $(\mathrm{p}=0.014)$. However, for other groups of cell viability showed no major differences (for each of $\mathrm{p}>0.05$ ).

$\alpha$-LA ameliorates renal dysfunction during $\mathrm{H}_{2} \mathrm{O}_{2}$-induced renal carcinoma

Alpha lipoic acid is a potent antioxidant that was shown to eliminate the effects of $\mathrm{H}_{2} \mathrm{O}_{2}$ damage on kidney tissue. It is formed

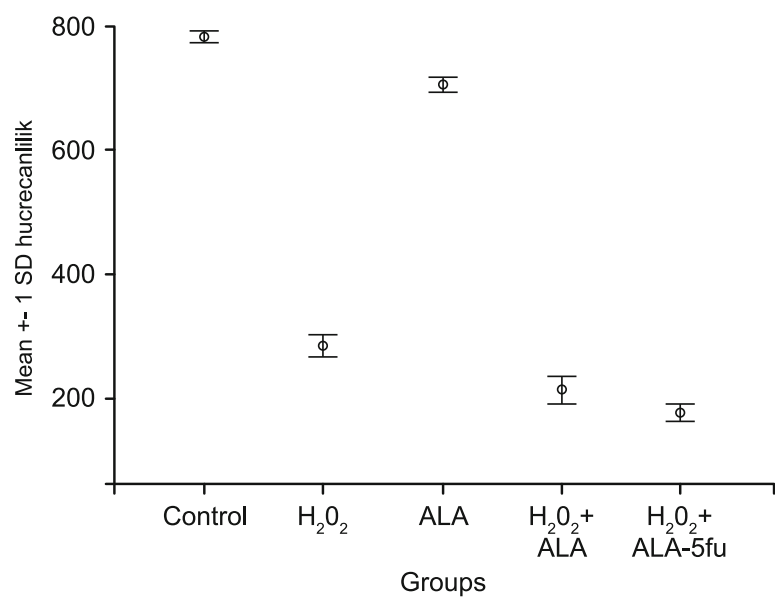

Fig. 1. Cell viability with MTT analysis.

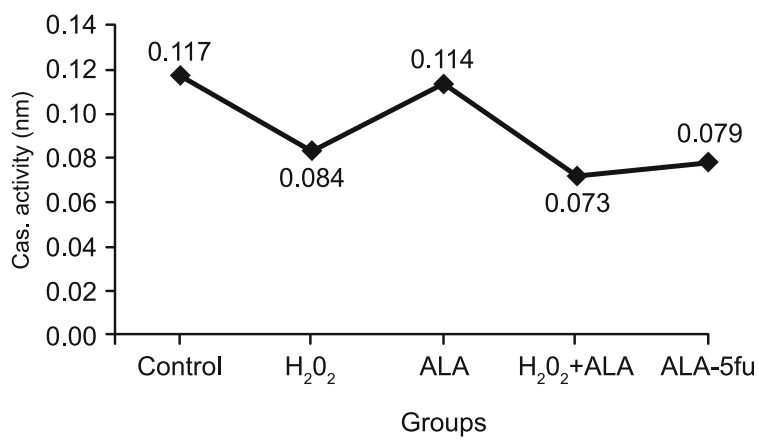

Fig. 2. Caspase 3 activity in different experimental groups.

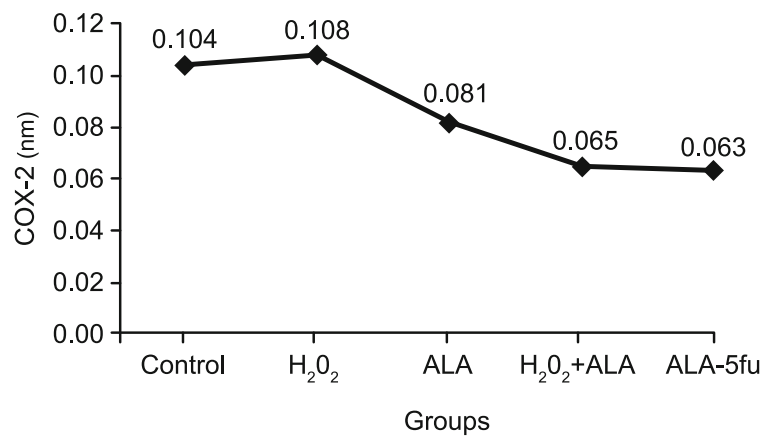

Fig. 3. COX-2 levels.

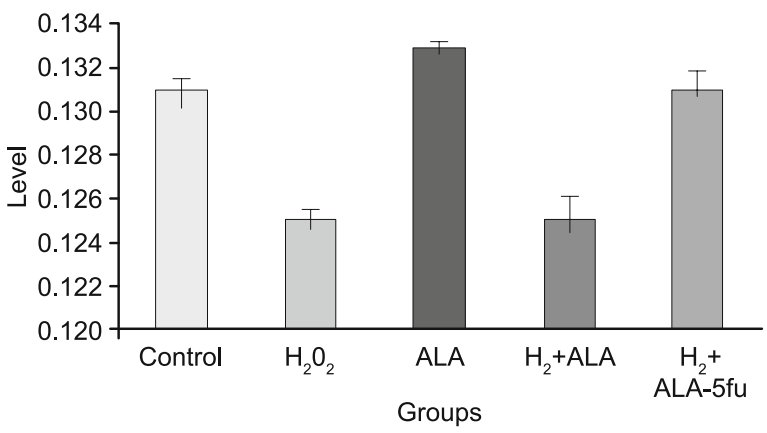

Fig. 4. Caspase 8 activities.

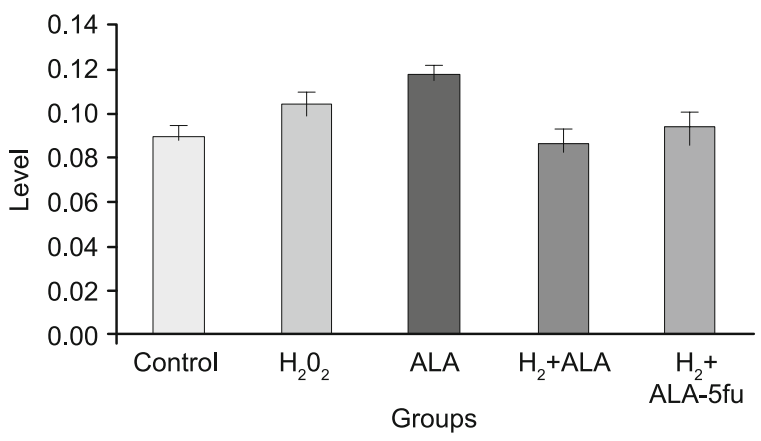

Fig. 5. Caspase 9 activities. 
through apoptosis by activating cell death domain via caspases on malignant renal cells. The effective dose of $\mathrm{H}_{2} \mathrm{O}_{2}$ was administered to provide oxidative stress conditions in order to prevent proliferation of renal cancer cells, correspondingly alpha lipoic acid has influenced the decreasing cytotoxic effects during cell death. Caspase 3 activities have shown expected effects related to cell viability in experimental groups (Fig. 2). Accordingly, Caspase 3 activity is raised significantly in alpha lipoic acid applied group in DNA damaged cells.

\section{$\alpha-L A$ inhibits $N F-\kappa B$ activation during oxidative stress in renal cell}

In apoptotic mechanism, Caspase 8 and Caspase 9 were determined to analyzed extrinsic and intrinsic pathways through reduced Caspase 3. Alpha lipoic acid induces cells under oxidative stress conditions with the same concentration and incubation times preferably through Caspase 8 pathway (Fig. 4). Although changing conditions, alpha lipoic acid is effective in both pathways for cell death mechanism while renal carcinoma has been influenced mostly through intrinsic pathway (Fig. 5). Caspase domains are associated indirectly with NF-kB activity. While caspase pathway activates with ALA for apoptosis, NF-kB transcription factor can be thrilled for inhibition.

\section{$\mathrm{H}_{2} \mathrm{O}_{2}$ induces $\mathrm{COX}-2$ expression during DNA damage-renal in- jury}

After caspase activities were evaluated, COX-2 levels were measured to determine the multiple roles of inflammation in relation to oxidative stress and cancer cell proliferation. COX-2 levels which are specified in Figure 3, have increased in $\mathrm{H}_{2} \mathrm{O}_{2}$ treated group depending on DNA damage upregulation, meanwhile this concentration has decreased in the antioxidant treated group associated with inflammation. Pro-oxidant behaviour of $\mathrm{H}_{2} \mathrm{O}_{2}$ is determined by COX-2 variation and it is thus directly correlated to caspase activity between their concentration on renal cell damage.

\section{Statistical analysis}

Our obtained results related to descriptive statistics are expressed as a mean, median, standard deviation, minimum and maximum data. Kruskal-Wallis test was used to compare the median cell viability test between experimental groups. Also Dunn test was used to examinate multiple comparisons in details. Statistical significance was taken as 0.05 and $\mathrm{p}<0.05$ was considered statistically significant. NCSS and SPSS (ver. PASW 18) software was used for data calculations.

\section{Discussion}

Mostly high levels of reactive oxygen radicals occur in malignant culture cells. For instance, in Szatrowski and Nathan research on several tumor cell lines, especially for tissue varieties, generated large amounts of $\mathrm{H}_{2} \mathrm{O}_{2}$ proliferatively. They noticed that pronounced $\mathrm{H}_{2} \mathrm{O}_{2}$ volume incubated after $4 \mathrm{~h}$ by these tumor cells was comparable to the amount of $\mathrm{H}_{2} \mathrm{O}_{2}$ produced by simi-
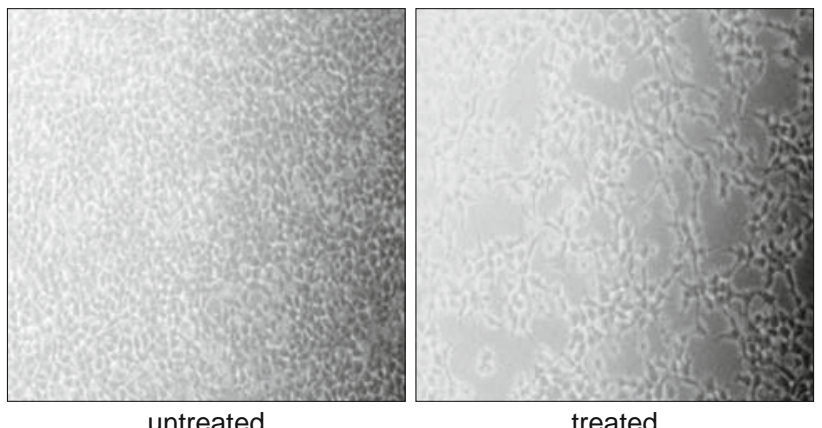

Fig. 6. Morphological analysis of $\mathrm{H}_{2} \mathrm{O}_{2}$ treatment.

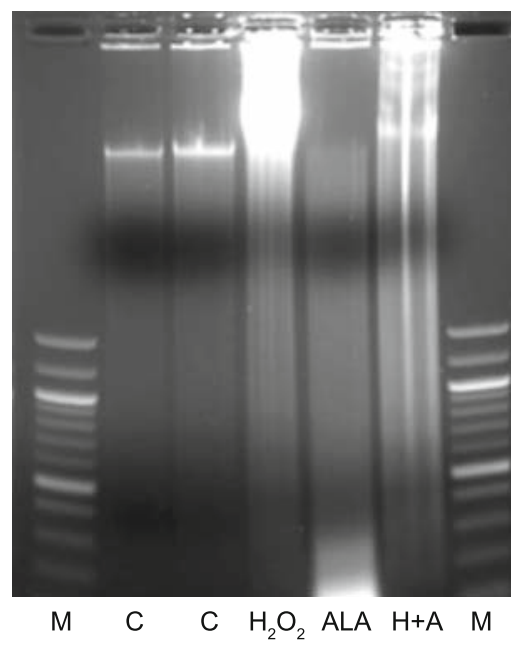

Fig. 7. DNA laddering in experimental groups.

lar numbers of phorbol ester-triggered neutrophils. $\mathrm{H}_{2} \mathrm{O}_{2}$ radicals have positive and negative effects on cells, sometimes can induce malignant transformation, and the malignant phenotype of tumor cells can be reversed by decreasing the levels of ROS (4).

Clinical research indicates that cancer is a genetic disease caused by the acquisition of multiple mutations in genes that control cell proliferation, cell death and genomic instability. Accumulating experimental data to determine increasing the cellular concentrations of reactive oxygen radicals can explain all initiation stages of cancer. It is known that an increase in the levels of $\mathrm{H}_{2} \mathrm{O}_{2}$ can lead to DNA damage, imbalance, and genetic mutations (14).

It is not fully clarified why different $\mathrm{H}_{2} \mathrm{O}_{2}$ concentrations (acts as a pro-oxidant agent) can kill cancer cells selectively. Tumor cells produce high levels of $\mathrm{H}_{2} \mathrm{O}_{2}$ than their normal collegues as shown in vitro and in vivo studies. Excessive amount of $\mathrm{H}_{2} \mathrm{O}_{2}$ accumulation in cells may lead to cell death through the induction of DNA damage. Cancer cells have mutations in DNA repair genes and can not properly repair specific types of DNA damage causing proliferation of cancer cells (15).

The findings demonstrate that prooxidant agents can increase the cellular levels of $\mathrm{H}_{2} \mathrm{O}_{2}$ and that glycolysis inhibitors can reduce the ca- 
pacity of cells to detoxify $\mathrm{H}_{2} \mathrm{O}_{2}$ (Fig. 6). Experimental datahave shown that malignant cells are more susceptible to glucose deprivation than nontransformed cells, and that an increase in the levels of $\mathrm{H}_{2} \mathrm{O}_{2}$ may mediate the cytotoxic effect induced by glucose deprivation (16).

Mostly cancer therapy perfomed as a surgery or radiotherapy has been effective when the disease is early detected. However many cancers are still diagnosed when cells from a primary tumor have already metastasized to other parts of the body. The main method of treatment at this point is chemotherapy, which consists of delivering drugs systemically so that they can reach and kill the tumor cells. But most of these drugs have severe side effects clinically and therefore are often used at suboptimal levels. Despite the recent interest by pharmaceutical companies in molecular modeling, combinatorial chemistry and other synthetic chemistry techniques, natural products and medicinal plants continue to be an important source of new drugs (17).

Natural products have made important role to the development of many anticancer drugs recently used in chemotherapy. Current observations suggest that prooxidant agents may represent a new class of anticancer drugs with high reactivity to target tumor cells selectively $(18,19)$.

The natural compounds react by several mechanisms such as inducing apoptosis via intrinsic or extrinsic pathway through DNA cleavage mediated by topoisomerase I or II inhibition (Fig. 7), mitochondrial permeabilization, inhibition of key enzymes involved in signal transduction, or cellular metabolism, and by inhibiting tumor-induced angiogenesis $(20,21)$.

One of popular flavonoids, ALA may prove useful in cancer treatment. ALA hasthe capability to induce hyperacetylation of histones: proteins capable of causing proliferation of many types of cancer cells. ALA may drive cancerous cells towards apoptosis during limiting histones. ALA has also been shown to be able to inhibit the protein complex NF-kB when combining drug applications. If activated, NF-kB is able to increase the survival of cancerous cells and increase cellular transformation, metastasis, invasion, proliferation, chemo-resistance, radio-resistance, and inflammation. ALA displays antimutagenic and anticlastogenic properties, which classify part of the natural antimutagenes group. When oxidizable substrates rise in cancer cell mitocondrias, ALA is also able to induce prooxidant agents driven apoptosis. Another mechanism of action of ALA is the ability to increase homocysteine levels in cancer cell lines to toxic concentrations for these malignant cells $(22,23)$.

Recent datas present that ALA occurs to have protective effect against $\mathrm{H}_{2} \mathrm{O}_{2}$-induced DNA damage. The study revealed chemopreventive as well as chemotherapeutic value of ALA. This antioxidant regenerates vitamin $\mathrm{E}$ from its oxidized form in biological systems. ALA supplementation with optimal concentration under various physiological and patho-physiological conditions causes decreasing oxidative stress and restores the normal levels of other antioxidants in vivo. High-dose ALA was seen maximum protection in studied several cell types. ALA and DHLA (its reduced form) application clarify ROS action in vitro model systems. ALA scavenges $\mathrm{OH} \cdot \mathrm{HOCl}$ and singlet oxygen for instance $\mathrm{H}_{2} \mathrm{O}_{2}$ by different mechanisms $(24,25,26,27)$.
The key point to fight against cancer using new therapies, it is necessary to understand the relation between flavonoids and the key enzymes related to neoplastic cells and metastasis in vitro and in vivo models (28).

\section{References}

1. Curti B, Jana BRP, Javeed M, Makhoul I, Sachdeva K, Hu W, Perry M, Talavera F, Harris JE. Renal Cell Carcinoma. Medscape Reference, 2014, WebMD.

2. López JI. Renal tumors with clear cells. A review. Pathol Res Pract 2013; 209 (3): 137-146. DOI: 10.1016/j.prp.2013.01.007. PMID 23433880.

3. Klinghoffer Z, Yang B, Kapoor A, Pinthus JH. Obesity and renal cell carcinoma: epidemiology, underlying mechanisms and management considerations. Expert Rev Anticancer Ther 2009; 9: 975-987.

4. Szatrowski TP, Nathan CF. Production of large amounts of hydrogen peroxide by human tumor cells. Cancer Res 1991; 51: 794-798.

5. Mantovani G, Maccio A, Madeddu C et al. Reactive oxygen species, antioxidant mechanisms, and serum cytokine levels in cancer patients: Impact of an antioxidant treatment. J Environ Pathol Toxicol Oncol 2003; 22: $17-28$.

6. Stenvinkel P. Inflammation as a target for improving health in chronic kidney disease. Med Rep 2010; 17 (1): 2-88.

7. Yang O, Maxwell P, Pollard P. Renal cell carcinoma: translational aspects of metabolism and therapeutic consequences. Kidney Internat 2013; 84: 667-681. DOI: 10.1038/ki.2013.245.

8. Sharoni Y, Linnewiel-Hermoni K, Khanin $\mathbf{M}$ et al. Carotenoids and apocarotenoids in cellular signaling related to cancer: a review. Mol Nutr Food Res 2012; 56: 259-269.

9. Uzzo RG, Rayman P, Kolenko V, Clark PE, Bloom T, Ward AM, Molto L, Tannenbaum C, Worford L, Bukowski R et al. Mechanisms of apoptosis in T cells from patients with renal cell carcinoma. Clin Cancer Res 1999; 5: 1219-1229.

10. Shi DY, Liu HL, Stern JS et al. Alpha-lipoic acid induces apoptosis in hepatoma cells via the PTEN/Akt pathway. FEBS Lett 2008; 582: $1667-1671$.

11. Meiyanto E, Hermawan Anindyajati A. Natural Products for CancerTargeted Therapy: Citrus Flavonoids as Potent Chemopreventive Agents. 2012. DOI: http: //dx.doi.org/10.7314/APJCP.2012.13.2.427

12. Wenzel U, Nickel A, Daniel H. A-lipoic acid induces apoptosis in human colon cancer cells by increasing mitochondrial respiration with a concomitant $\mathrm{O} 2$ generation. Apoptosis 2005; 10: 359-368.

13. Schupke H, Hempel R, Peter G, Hermann R, Wessel K, Engle J, Kronbach T. New metabolic pathways of a-lipoic acid. Drug Metab Dispos 2001; 29 (6): 855-862.

14. Vogelstein B, Kinzler KW. Cancer genes and the pathways they control. Nat Med 2004; 10: 789-799.

15. Arnold RS, Shi J, Murad E et al. Hydrogen peroxide mediates the cell growth and transformation caused by the mitogenic oxidase Nox1. Proc Natl Acad Sci 2001; 98: 5550-5555.

16. Aykin-Burns N, Ahmad IM, Zhu Y, Oberley LW, Spitz DR. Increased levels of superoxide and $\mathrm{H}_{2} \mathrm{O}_{2}$ mediate the differential susceptibility of cancer cells versus normal cells to glucose deprivation. Biochem J 2009; 418: 29-37. 
89-94

17. Hurley LH. DNA and its associated processes as targets for cancer therapy. Nature Reviews Cancer 2002; 2: 188-200.

18. Hanahan D, Weinberg RA. The hallmarks of cancer. Cell 2000; 100 : $57-70$.

19. Yurdakok B, Alpay M, Kismali G et al. In Vitro Effects of Phthalate Mixtures on Colorectal Adenocarcinoma Cell Lines DLD1 and HT29. DOI: 10.1615/JEnvironPatholToxicolOncol.2015013256.

20. Neumann CS, Fujimori DG, Walsh CT. Halogenation strategies in natural product biosynthesis. Chem Biol 2008; 15: 99-109.

21. Meral O, Alpay M, Kismali G et al. Capsaicin inhibits cell proliferation by cytochrome $\mathrm{c}$ release in gastric cancer cells. Tumor Biology 2014; 35 (7).

22. Goraca A, Huk-Kolega H, Piechota A, Kleniewska P, Ciejka E, Skibska B. Lipoic acid - biological activity and therapeutic potential. Pharmacol Rep 2011; 63 (4): 849-858.
23. Berkson BM, Rubin DM, Berkson AJ. Revisiting the ALA/N (alphalipoic acid/low-dose naltrexone) protocol for people with metastatic and nonmetastatic pancreatic cancer: a report of 3 new cases. Integr Cancer Ther 2009; 8 (4): 416-422.

24. Packer L, Witt EH, Tritschler HJ. Alpha lipoic acid as a biological anti-oxidant. Free Radic Biol Med 1995; 19: 227-250.

25. Packer L, Suzuki YJ. Vitamin E and alpha-lipoate: role in antioxidant recycling and activation of the NF-kappa $\beta$ transcription factor. Mol Aspects Med 1993; 14: 229-239.

26. Somani SM, Hussain K, Whiteworth C, Trammell GL, Malafa M, Rybak LP. Dose dependent protection by lipoic acid against cisplatininduced nephrotoxicity in rats: antioxidant defense system. Pharmacol Toxicol 2000; 86: 234-241.

27. Batra Priya, Sharma A. Anticancer potential of flavonoids. Biotech 2013; 3: 439-459. 